\title{
Review Article \\ Prediction of Preterm Birth: Maternal Characteristics, Ultrasound Markers, and Biomarkers: An Updated Overview
}

\author{
Zeynep Asli Oskovi Kaplan $(\mathbb{D})$ and A. Seval Ozgu-Erdinc \\ University of Health Sciences, Dr. Zekai Tahir Burak Women's Health Care, Education and Research Hospital, Ankara, Turkey \\ Correspondence should be addressed to Zeynep Asli Oskovi Kaplan; aslioskovi@gmail.com
}

Received 19 November 2017; Revised 9 August 2018; Accepted 10 September 2018; Published 10 October 2018

Academic Editor: Padma Murthi

Copyright (c) 2018 Zeynep Asli Oskovi Kaplan and A. Seval Ozgu-Erdinc. This is an open access article distributed under the Creative Commons Attribution License, which permits unrestricted use, distribution, and reproduction in any medium, provided the original work is properly cited.

\begin{abstract}
There is not a single or combined screening method for preterm birth with high sensitivity which will truly identify the women at risk for preterm birth while also with high specificity to prevent unnecessary interventions and high treatment costs. Measurement of cervical length is the most cost-effective method that is used in clinical practice. Bedside tests have also been developed for detecting markers like fetal fibronectin, insulin-like growth factor binding protein-1 (IGFBP-1), interleukin-6, and placental alpha-macroglobulin-1. Taking the maternal history, health condition, and sociodemographical factors into consideration is recommended. Ultrasound markers apart from cervical length measurements as uterocervical angle and placental strain ratio are studied. Investigations on metabolomics, proteomics, and microRNA profiling have brought a new aspect on this subject. Maybe in the future, with clear identification of women at true risk for preterm birth, development of more effective preventive strategies will not be unfeasible.
\end{abstract}

\section{Introduction}

Defined as delivery before completing 37 weeks of gestation, $\mathrm{PB}$ is caused by multiple etiologies as individual and environmental factors, which makes the prediction and prevention of $\mathrm{PB}$ a challenging process in antenatal care [1]. Preterm birth $(\mathrm{PB})$ is an important subject for being one of the leading causes of neonatal mortality and its long term neurologic and developmental problems [1]. It is related with cerebral palsy, bronchopulmonary dysplasia, retinopathy of prematurity, and many other morbidities that come with the prematurity [1].

In 2010, there were 15 million preterm births ( $<37$ weeks' gestation) worldwide, with a prevalence of 5-18\% of live births $[2,3]$. In 2015, PB rate in United States was 9.62\% among $3,977,745$ births which meant significant number of neonates needed further medical care [4]. PB is a complex condition resulting from multiple etiologic pathways [5]. PB may be iatrogenic due to medical interventions for maternal and fetal indications, whereas $80 \%$ of PB occur spontaneously; and while 1 million children die because of prematurity, more survive the consequences of $\mathrm{PB}[3]$.
Foresight of preterm labor enables taking early action for preterm birth as in utero transfer to tertiary care centers, reasonable administration of corticosteroids while avoiding unnecessary use, magnesium sulfate treatment for neuroprotective effect, and antibiotic treatment in case of infection. As underlying etiology of preterm labor is not completely clear, identification of risk factors and determining the individual risk for pregnant women have importance in obstetric management of women who may benefit from current treatment strategies [6] (Table 1).

\section{Maternal Characteristics}

2.1. Obstetric History. Women with a history of prior preterm birth in previous pregnancy have an increased risk for preterm birth in subsequent pregnancy. In a study by Iams et al. [7] risk of recurrent PB ( $<35$ weeks) was $14-15 \%$ while women with a previous history of uncomplicated term delivery had $3 \%$ risk for spontaneous term delivery. By taking the increased risk for $\mathrm{PB}$ into consideration in women with preterm birth history, precautions like cervical length screening or progesterone administration and intervention 
TABLE 1: Risk factors for preterm birth (adopted from Koulali and Frey) $[5,6]$.

\begin{tabular}{l}
\hline Maternal characteristics \\
\hline Family history of preterm birth \\
\hline Low socio-economic status \\
\hline Low educational attainment \\
\hline Maternal age (low and high) \\
\hline Ethnicity \\
\hline Stress \\
\hline Depression \\
\hline Tobacco use \\
\hline Low body mass index \\
\hline Infections (genitourinary or extra genital) \\
\hline Periodontal disease \\
\hline Uterine anomalies \\
\hline History of cervical excisional procedures/surgery \\
(LEEP/conization) \\
\hline Reproductive history \\
\hline Prior preterm birth \\
\hline Prior stillbirth/ Pregnancy loss $>16$ weeks GA \\
\hline Induced abortion \\
\hline Cervical insufficiency \\
\hline Current pregnancy characteristics \\
\hline Vaginal bleeding \\
\hline Use of assisted reproductive technologies \\
\hline Multiple gestation \\
\hline Shortyhydramnios \\
\hline
\end{tabular}

for maternal risk factors like smoking cessation, treatment of underlying maternal comorbidities, and achieving ideal body mass index should be considered in this population $[8,9]$. Recent comprehensive studies showed history of spontaneous abortion and recurrent pregnancy loss was associated with increased risk of $\mathrm{PB}$ [10], while induced abortion was not found as a risk factor for $\mathrm{PB}$ in subsequent pregnancy of firsttime mothers [11]. Repeat terminations of pregnancy were associated with high risk for extremely PB [12]. Interpregnancy interval $\leq 6$ or $>6$ months, following dilatation and evacuation in $14-26$ weeks, also did not increase the risk of $\mathrm{PB}[13]$.

\subsection{Maternal Body Mass Index (BMI) and Gestational Weight} Gain. There are controversial reports of authors in literature about the influence of maternal BMI on preterm delivery risk. Maternal underweight was reported as a risk factor for $\mathrm{PB}$, low birth weight, and being small for gestational age infant in developed countries [14]. A study which examined 12,526 women reported that, among underweight and normal weight women, neither low gestational weight gain nor gestational weight gain pattern in first and second trimester of pregnancy was associated with PB [15].
2.3. Maternal Infections. Alkaline vaginal $\mathrm{PH}$, which could be a result of bacterial vaginosis, was proposed as a predictor of $\mathrm{PB}$. Risk of PB was found 3-fold increased when vaginal $\mathrm{PH}$ was $>5$ [16]. Also alkaline vaginal $\mathrm{PH}$ was found more accurate to predict late $\mathrm{PB}(34-37$ weeks) than early $\mathrm{PB}(<34$ weeks) [16].

Urogenital infections were found to increase the risk of preterm birth [17].

A meta-analysis of six observational case-control studies and four cohort studies involving 6781 patients with preterm labor showed that chronic hepatitis B infection was not a risk factor for PB [18].

Human papilloma virus (HPV) prevalence was reported as $17.5 \%$ for cervix (with a great variation ranging from $2.2 \%$ to $75 \%$ in different geographical locations) in normal full term pregnancies while it was $45 \%$ in pregnancies which resulted in preterm deliveries [19]. There was a correlation between HPV, especially high-risk genotypes (HPV 16 and 18), and spontaneous preterm labor in a study from Egypt [20]. Viral load of HPV was positively correlated with the rate of MMP2 gene expression and both had significant effect on gestational age.

2.4. Periodontal Disease. Periodontitis is the most common chronic infectious disease which is a significant multibacterial reservoir and source for proinflammatory cytokines. In literature, there is not an absolute consensus since periodontitis is associated with $\mathrm{PB}$, while most systematic reviews and literature reported an increased risk for $\mathrm{PB}$ and low birth weight infants [21]. No reduction has been demonstrated in $\mathrm{PB}$ with treatment of periodontal disease in pregnancy [22].

2.5. Maternal Vitamin D Deficiency. There are controversial studies in literature about the role of vitamin $\mathrm{D}$ in $\mathrm{PB}$ reporting that there is no association between vitamin $\mathrm{D}$ and $\mathrm{PB}$ [23], risk of $\mathrm{PB}$ increases when serum vitamin $\mathrm{D}$ concentrations are less than $20 \mathrm{ng} / \mathrm{mL}$ [24], and prevalence of PB is higher when vitamin $\mathrm{D}$ concentrations are higher than $30 \mathrm{ng} / \mathrm{mL}$ [25]. A meta-analysis, including 10,098 subjects from 10 studies, reported that risk of $\mathrm{PB}$ was higher in pregnant women with vitamin $\mathrm{D}$ deficiency $(<20 \mathrm{ng} / \mathrm{mL})[26]$.

\section{Ultrasound Markers}

3.1. Cervical Length. Screening of cervical length by transvaginal ultrasound is a good predictor of $\mathrm{PB}$ risk in singleton pregnancies. Threshold of cervical length in 24 weeks of gestation for PB risk was defined as $25 \mathrm{~mm}$ ( $10^{\text {th }}$ percentile), with $37.3 \%$ sensitivity and $92.2 \%$ specificity [27]. A metaanalysis showed that the knowledge of cervical length had a reduced risk for $\mathrm{PB}$ before 37 weeks [28]. A recent study in an extensive population reported that universal cervical screening program during mid-trimester sonogram in women without a history of preterm birth was associated with reduction in the PB [29].

Women with twin gestation were screened for serial cervical length measurements between 14-18 weeks and 28-32 weeks; it was reported that cervical length had four patterns 
as stable, early-rapid shortening, late-shortening, and early shortening with a plateau and each pattern had different risk of $\mathrm{PB}$ while highest risk was in early-rapid shortening group [30]. However, cervical length assessed in mid-trimester asymptomatic twin pregnancies was a poor predictor of $\mathrm{PB}$ $<32$ weeks' gestation [31].

Within 3-week period, a shortening in cervical length $>10 \%$ was found associated with increased risk of PB [32].

Among women with threatened preterm labor, cervical length was assessed in women with and without cervical dilatation. It was reported that risk for PB was higher in women with cervical dilatation, while short cervical length was independently associated with preterm birth [33]. A cervical length $\leq 15 \mathrm{~mm}$ was reported as the most optimal cut-off with $81 \%$ specificity and $83 \%$ positive predictive value for predicting the true preterm labor [34].

There has been a conflicting evidence on screening of cervical length in the first trimester (11-13 weeks) $[35,36]$. History of $\mathrm{PB}$, maternal characteristics, and smoking may play a more important role in determining the risk of $\mathrm{PB}$ in the first trimester $[35,36]$.

3.2. Cervical Consistence. Cervical length is only a morphologic analysis and cervix has consistence and structural changes during labor. Two methods have been described for assessment of cervical elastography: strain elastography and shear wave elastography [37]. These methods are promising but there are limitations in technical implementations. Therefore cervical elastography, which is not yet a clearly identified subject, is proposed to be a possible alternative in the future which may be combined with cervical length [38].

Cervical consistency index (CCI), formulated as $\left(\mathrm{AP}^{1} /\right.$ AP) $\mathrm{x} 100$, measuring anteroposterior cervical diameter before (AP) and after $\left(\mathrm{AP}^{1}\right)$ is reported as being more effective than cervical length in prediction of $\mathrm{PB}[39,40]$.

3.3. Newer Tools. In low risk population at 20-24 weeks of gestation; combination of anterior cervical angle, cervical length, and maternal characteristics was reported to have a chance to predict approximately $40 \%$ of severe preterm births [41]. Uterocervical angle (between lower uterine segment and cervical canal) $\geq 95^{\circ}$ and $\geq 105^{\circ}$ detected in second trimester indicated an increased risk for $\mathrm{PB}<37$ and $<34$ weeks, respectively [42].

The current data on association of fetal membrane thickness and premature rupture of membranes was found insufficient to determine a potential risk [43].

Uterine artery pulsatility index during peak uterine contraction in women with threatened preterm labor was found significantly higher in women who delivered within 7 days [44].

Placental strain ratio, when measured with real-time sonoelastography, was found negatively correlated with gestational age at birth and it was suggested to be an effective predictor for PB [45].

Measurement of central zone of fetal adrenal gland was found effective in predicting PB within 7 days with a similar accuracy to cervical length measurement [46].
Lower fetal middle cerebral artery pulsatility index (MCA-PI) values were found associated with an earlier onset of labor which may be caused by fetal hypoxemia unrelated to placental disease, while uterine artery Doppler and cerebroplacental ratio did not have correlation with PB [47]. However MCA-PI was reported as a poor predictor of $\mathrm{PB}$, which was unlikely to be useful in clinical practice [47].

\section{Biomarkers}

4.1. Cervical Fluid. Fetal fibronectin is a glycoprotein which is produced by amniocytes and cytotrophoblasts that binds chorionic membranes to maternal decidua. It is normally found in cervicovaginal fluids before 22 weeks of gestation but its presence in cervicovaginal fluid between 24 and 34 weeks of gestation indicates a risk for $\mathrm{PB}$. A systematic review reported that although the accuracy of fetal fibronectin in predicting spontaneous $\mathrm{PB}$ varied, it is most accurate in predicting preterm birth in women with threatened preterm labor without advanced cervical dilatation within 7-10 days after testing [48]. However, a recent meta-analysis reported that fetal fibronectin testing in singleton gestations was not associated with prevention of $\mathrm{PB}$ or improved perinatal outcomes, reporting that $\mathrm{PB}$ incidences before 28 weeks, 32 weeks, 34 weeks, and 37 weeks did not change despite its higher costs [49].

While testing fetal fibronectin, blood-stained swabs were still effective in predicting PB; however they had higher false positive rates [50].

Value of quantitative fetal fibronectin measurement combined with cervical length was compared with qualitative fetal fibronectin combined with cervical length and it was found that it did not improve the prediction of $\mathrm{PB}$ within 7 days while it added value to determine risk range [51]. Recently, accuracy of combined serial cervical length measurements and fetal fibronectin for predicting $\mathrm{PB}$ in nulliparous patients was reported to be low [52].

IL-6 and IL-8 levels in cervicovaginal fluid were associated with $\mathrm{PB}$ within 7 days and successful when especially combined with cervical length. Combination of IL-8 levels and cervical length had a specificity of $92.8 \%$ for predicting PB in 7 days; however its relatively low sensitivity (56.4\%) was a limitation for its clinical use [53].

Placental alpha macroglobulin-1 (PAMG-1), which is assessed by a bedside test PartoSure, was compared with fetal fibronectin and cervical length measurement and it was reported that PartoSure was more accurate in predicting PB within 7 days with $80 \%$ sensitivity and $95 \%$ specificity and it was reported that PartoSure had the greatest utility in patients when cervical length was $15-35 \mathrm{~mm}$ [54].

Insulin-like growth factor binding protein-1 (IGFBP-1) was requested as a marker for predicting $\mathrm{PB}$ for being positive at significantly higher rates in cervical fluids of patients with PB [55]. Premaquick $\odot$, developed as a triple biomarker of native and total IGFBP-1 and IL-6, was reported as a successful test with $87.1 \%$ sensitivity, $92.4 \%$ specificity, $84.4 \%$ PPV, $100 \%$ NPV, and 95\% accuracy in predicting PB in 7 days [56]. When combined with cervical length, Actim Partus test (IGFBP-1) was suggested as an alternative for fetal fibronectin 
to identify the women who are at risk of delivering in 7 days [57]. Another study reported that bedside test for IGFBP-1 was more reliable in prediction of $\mathrm{PB}$ than fetal fibronectin test [58].

A recent meta-analysis compared PAMG-1, fetal fibronectin, and phosphorylated (IGFBP-1) in symptomatic women, and PAMG-1 was reported to have the highest positive predictive value and positive likelihood ratio $(\mathrm{LR}+)$ while negative predictive value and LR- remained similarly high within the three biomarkers [59].

4.2. Amniotic Fluid. Low amniotic fluid glucose was found associated with preterm delivery in patients who had undergone amniocentesis at 16-22 weeks of pregnancy for standard indications [60]. Interleukin-6 (IL-6) in amniotic fluid in second trimester was found negatively correlated with gestational age at delivery [61]. In contradiction, another prospective study did not find significant difference in terms of IL-6, matrix metalloproteinase-9 (MMP-9), glucose, and Creactive protein (CRP) in mid-trimester amniotic fluid [62]. Maternal serum acute phase reactants were studied in women with threatened preterm labor compared with healthy controls and lower serum albumin and higher serum ferritin levels were reported in women with threatened preterm labor [63]. In asymptomatic mid-trimester women undergoing amniocentesis, rapid bedside test of matrix metalloproteinase-8 (MMP-8) was reported to predict nearly half of spontaneous preterm births [64].

In amniotic fluid, increased vascular endothelial growth factor (VEGF), placental growth factor (PGF), and decreased soluble VEGF receptor-1 (sFlt-1) at 16-19 weeks of gestation, which were indicating angiogenesis and tendency for inflammation, were predictive for PB [65].

Elevated levels of interleukin-1 $\beta$ (IL- $1 \beta$ ) due to possible infection or inflammation, in amniotic fluid and cervicovaginal fluid, were suggested as a potential predictor of $\mathrm{PB}$ [66]. However, investigations do not have an active role yet in clinical practice in prediction of $\mathrm{PB}$ and further studies are needed for clinical use of IL-1 targeting therapies for prevention of PB [66].

Neutrophil elastase levels in amniotic fluid were investigated for predicting PB, following emergent cerclage [67]. Duration of pregnancy was reported significantly longer in patients after emergent cerclage when neutrophil elastase levels in amniotic fluid were $<180 \mathrm{ng} / \mathrm{mL}$.

IL-8 and Annexin-A2 levels were measured in amniotic fluid that developed $\mathrm{PB}<32$ weeks either with or without preterm premature rupture of membranes (PPROM); and combination of amniotic fluid IL-8 and Annexin-A2 for predicting PB within 2 weeks was reported to have a sensitivity of $81.25 \%$, specificity of $88.89 \%$, and positive predicting value (PPV) of $92.86 \%$ [68].

4.3. Maternal Serum Markers. Maternal serum calponin 1 was found significantly high in patients who delivered preterm within 7 weeks and was requested as biomarker for a short-term prediction of PB [69].

Ratio of maternal serum alpha fetoprotein (AFP)/amniotic fluid AFP was suggested as a potential predictor for intrauterine growth restriction and preterm delivery in a small sample sized study [70].
Maternal serum progesterone-induced blocking factor (PIBF) was found significantly lower in patients within 5 days prior to PB [71].

Maternal plateletcrit count was found significantly higher in patients who delivered preterm; a cut-off value of $0.201 \%$, with a sensitivity of $95.6 \%$ and specificity of $87.5 \%$, was reported [72].

Maternal salivary estriol, measured in 25-34 weeks, had $82 \%$ negative predictive value on identifying women who will not deliver preterm, which could be used for avoiding unnecessary interventions to prevent PB [73].

\section{Molecular Techniques}

Production of 25 proteins in maternal serum at 16-17 weeks of gestation was analyzed and proteomic imbalance (downregulation and upregulation) in 25 proteins as antioxidant enzymes, chaperons, cytoskeleton proteins, cell adhesion molecules, and proteins involved in angiogenesis, proteolysis, transcription, inflammation, binding, and transportation of various ligands was detected [74]. This means that changes that promote PB start as early as second trimester.

It was also suggested that metabolic profiling of amniotic fluid may help identifying fetuses at risk for developing bronchopulmonary dysplasia as well as the risk for PB [75].

Preterm SAMBA study was intended to study metabolomics techniques in multiethnic populations to investigate multiple complex underlying determinants in etiology of spontaneous PB which have not been enlightened yet [76].

MicroRNA profiles were assessed in maternal blood and it was reported that a correlation with $\mathrm{PB}$ was not detected [77].

\section{Conclusion}

Recently, the prophylactic use of progesterone, pessary, and cerclage in women with high risk of $\mathrm{PB}$ has been reported to reduce the incidence of $\mathrm{PB}$ and improve neonatal outcomes. These results highlight the importance of prediction models in order to establish preventative strategies early in pregnancy. Currently, there are no tools that enable early prediction of those women susceptible to $\mathrm{PB}$ and more research is needed to develop new strategies to identify women who may benefit from prophylactic therapy.

Not a single biomarker has been evolved till date, which possesses sensitivity as well as reliability for the detection of spontaneous $\mathrm{PB}$. The variability in results of the studies may be caused by different study designs and diversities in the study population. Study on a large sample size is needed to confirm the effectiveness of a biomarker. A single biomarker or even in combination, if found for the prediction of $\mathrm{PB}$, can decrease the hospital cost and restrict the treatment.

Identification of risk factors early in pregnancy is an essential component of clinical obstetric care, since early interventions may be effective in reducing the risk of $\mathrm{PB}$. Preconceptional counselling regarding these factors may further reduce the risk of $\mathrm{PB}$ [6]. Differentiation of severity of risk factors is important to assess the best strategy to prevent $\mathrm{PB}$. The prevention of $\mathrm{PB}$ is a major public health priority 
aiming to reduce the infant and childhood morbidity and mortality. One of the greatest challenges in studying this outcome is that $\mathrm{PB}$ is a complex condition caused by multiple etiologic pathways [78].

Yet, none of the screening tests reported previously can fulfill the criteria for ideal screening test. Therefore, further well designed studies investigating the predictive value of biomarkers and other screening methods predicting preterm delivery with high sensitivity and specificity are still warranted.

Many findings such as maternal risk factors, ultrasound markers, and biomarkers in maternal serum, amniotic fluid, or cervical fluid are defined in literature that can be effective in predicting PB [79]. There is not a routine method recommended for screening $\mathrm{PB}$ in asymptomatic low risk population. Measurement of cervical length by transvaginal ultrasound is the only cost-effective method in women with history of PB or symptoms of threatened PB. However, even if risk of preterm birth is determined, it cannot be precisely prevented recently in eligible practice.

\section{Conflicts of Interest}

The authors declare that there are no conflicts of interest regarding the publication of this paper.

\section{References}

[1] H. Blencowe, S. Cousens, M. Z. Oestergaard et al., "National, regional, and worldwide estimates of preterm birth rates in the year 2010 with time trends since 1990 for selected countries: a systematic analysis and implications," The Lancet, vol. 379, no. 9832, pp. 2162-2172, 2012.

[2] H. Torchin and P.-Y. Ancel, "Epidemiology and risk factors of preterm birth," Journal de Gynécologie Obstétrique et Biologie de la Reproduction, vol. 45, no. 10, pp. 1213-1230, 2016.

[3] WHO, "Preterm birth 2016 [updated November 201624/3/ 2017]," http://www.who.int/mediacentre/factsheets/fs363/en/.

[4] B. Hamilton, J. Martin, and M. Osterman, "Births: Preliminary Data for 2015," National Vital Statistics Reports, vol. 66, no. 3, 2016.

[5] H. A. Frey and M. A. Klebanoff, "The epidemiology, etiology, and costs of preterm birth," Seminars in Fetal \& Neonatal Medicine, vol. 21, no. 2, pp. 68-73, 2016.

[6] B. Koullali, M. A. Oudijk, T. A. Nijman, B. W. Mol, and E. Pajkrt, "Risk assessment and management to prevent preterm birth," Seminars in Fetal \& Neonatal Medicine, vol. 21, no. 2, pp. 80-88, 2016.

[7] J. D. Iams, R. L. Goldenberg, B. M. Mercer et al., “The Preterm Prediction Study: Recurrence risk of spontaneous preterm birth," American Journal of Obstetrics \& Gynecology, vol. 178, no. 5, pp. 1035-1040, 1998.

[8] J. L. Wallace, K. L. Aland, K. Blatt, E. Moore, and E. A. DeFranco, "Modifying the risk of recurrent preterm birth: influence of trimester-specific changes in smoking behaviors," American Journal of Obstetrics \& Gynecology, vol. 216, no. 3, pp. 310310.e8, 2017.

[9] L. C. Colicchia and H. N. Simhan, "Optimizing Subsequent Pregnancy Outcomes for Women with a Prior Preterm Birth,"
American Journal of Perinatology, vol. 33, no. 3, pp. 267-275, 2016.

[10] R. Omani-Samani, M. A. Mansournia, M. Sepidarkish et al., "Cross-sectional study of associations between prior spontaneous abortions and preterm delivery," International Journal of Gynecology and Obstetrics, vol. 140, no. 1, pp. 81-86, 2018.

[11] L. Ke, W. Lin, Y. Liu, W. Ou, and Z. Lin, "Association of induced abortion with preterm birth risk in first-time mothers," Scientific Reports, vol. 8, no. 1, 2018.

[12] S. Kc, M. Gissler, S. M. Virtanen, and R. Klemetti, "Risks of adverse perinatal outcomes after repeat terminations of pregnancy by their methods: a nationwide register-based cohort study in finland 1996-2013," Paediatric and Perinatal Epidemiology, vol. 31, no. 6, pp. 485-492, 2017.

[13] M. Kuwahara, K. Yamasato, M. Tschann, and B. Kaneshiro, "Interpregnancy interval and subsequent pregnancy outcomes after dilation and evacuation," Journal of Obstetrics \& Gynaecology, vol. 38, no. 4, pp. 516-520, 2018.

[14] Z. Han, S. Mulla, J. Beyene, G. Liao, and S. D. McDonald, "Maternal underweight and the risk of preterm birth and low birth weight: A systematic review and meta-analyses," International Journal of Epidemiology, vol. 40, no. 1, pp. 65-101, 2011.

[15] A. J. Sharma, K. K. Vesco, J. Bulkley et al., "Associations of Gestational Weight Gain with Preterm Birth among Underweight and Normal Weight Women," Maternal and Child Health Journal, vol. 19, no. 9, pp. 2066-2073, 2015.

[16] F. Foroozanfard, Z. Tabasi, E. Mesdaghinia, M. Sehat, and M. Mahdian, "Cervical length versus vaginal $\mathrm{PH}$ in the second trimester as preterm birth predictor," Pakistan Journal of Medical Sciences, vol. 31, no. 2, pp. 374-378, 1969.

[17] I. Verma, K. Avasthi, and V. Berry, "Urogenital Infections as a Risk Factor for Preterm Labor: A Hospital-Based Case-Control Study," The Journal of Obstetrics and Gynecology of India, vol. 64, no. 4, pp. 274-278, 2014.

[18] Q. Huang, S. Wei, M. Zhong et al., “Chronic hepatitis B infection and risk of preterm labor: A meta-analysis of observational studies," Journal of Clinical Virology, vol. 61, no. 1, pp. 3-8, 2014.

[19] L. M. Ambuhl, U. Baandrup, K. Dybkaer, J. Blaakaer, N. Uldbjerg, and S. Sørensen, "Human Papillomavirus Infection as a Possible Cause of Spontaneous Abortion and Spontaneous Preterm Delivery," Infectious Diseases in Obstetrics and Gynecology, vol. 2016, Article ID 3086036, 19 pages, 2016.

[20] A. Mosbah, R. Barakat, Y. Nabiel, and G. Barakat, "High-risk and low-risk human papilloma virus in association to spontaneous preterm labor: a case-control study in a tertiary center, Egypt," The Journal of Maternal-Fetal \& Neonatal Medicine : The Official Journal of the European Association of Perinatal Medicine, the Federation of Asia and Oceania Perinatal Societies, the International Society of Perinatal Obstet, vol. 06, pp. 1-6, 2017.

[21] H. Ren and M. Du, "Role of Maternal Periodontitis in Preterm Birth," Frontiers in Immunology, vol. 8, 2017.

[22] G. A. Macones, S. Parry, D. B. Nelson et al., "Treatment of localized periodontal disease in pregnancy does not reduce the occurrence of preterm birth: results from the Periodontal Infections and Prematurity Study (PIPS)," American Journal of Obstetrics \& Gynecology, vol. 202, no. 2, pp. 147.el-147.e8, 2010.

[23] A. J. Rodríguez, V. D. S. Nunes, C. A. Mastronardi, T. Neeman, and G. J. Paz-Filho, "Association between circulating adipocytokine concentrations and microvascular complications in patients with type 2 diabetes mellitus: A systematic review and meta-analysis of controlled cross-sectional studies," Journal of Diabetes and its Complications, vol. 30, no. 2, pp. 357-367, 2016. 
[24] C. L. Wagner, C. Baggerly, S. L. McDonnell et al., "Post-hoc comparison of vitamin D status at three timepoints during pregnancy demonstrates lower risk of preterm birth with higher vitamin D closer to delivery," The Journal of Steroid Biochemistry and Molecular Biology, vol. 148, pp. 256-260, 2015.

[25] J. Zhou, L. Su, M. Liu et al., "Associations between 25-hydroxyvitamin D levels and pregnancy outcomes: A prospective observational study in southern China," European Journal of Clinical Nutrition, vol. 68, no. 8, pp. 925-930, 2014.

[26] L. Qin, F. Lu, S. Yang, H. Xu, and B. Luo, "Does Maternal Vitamin D Deficiency Increase the Risk of Preterm Birth: A MetaAnalysis of Observational Studies," Nutrients, vol. 8, no. 5, p. 301, 2016.

[27] J. D. Iams, R. L. Goldenberg, P. J. Meis et al., "The Length of the Cervix and the Risk of Spontaneous Premature Delivery," The New England Journal of Medicine, vol. 334, no. 9, pp. 567-573, 1996.

[28] V. Berghella, M. Palacio, A. Ness, Z. Alfirevic, K. H. Nicolaides, and G. Saccone, "Cervical length screening for prevention of preterm birth in singleton pregnancy with threatened preterm labor: systematic review and meta-analysis of randomized controlled trials using individual patient-level data," Ultrasound in Obstetrics \& Gynecology: The Official Journal of the International Society of Ultrasound in Obstetrics and Gynecology, vol. 49, no. 3, pp. 322-329, 2017.

[29] M. Son, W. A. Grobman, N. K. Ayala, and E. S. Miller, "A universal mid-trimester transvaginal cervical length screening program and its associated reduced preterm birth rate," American Journal of Obstetrics \& Gynecology, vol. 214, no. 3, pp. 365.e1365.e5, 2016.

[30] N. Melamed, A. Pittini, L. Hiersch et al., "Serial cervical length determination in twin pregnancies reveals 4 distinct patterns with prognostic significance for preterm birth," American Journal of Obstetrics \& Gynecology, vol. 215, no. 4, pp. 476-476.ell, 2016.

[31] G. Pagani, V. Stagnati, A. Fichera, and F. Prefumo, "Cervical length at mid-gestation in screening for preterm birth in twin pregnancy," Ultrasound in Obstetrics \& Gynecology, vol. 48, no. 1, pp. 56-60, 2016.

[32] J. Blanc and F. Bretelle, "Outils prédictifs de l'accouchement prématuré dans une population asymptomatique à haut risque," Journal de Gynécologie Obstétrique et Biologie de la Reproduction, vol. 45, no. 10, pp. 1261-1279, 2016.

[33] L. Hiersch, N. Melamed, A. Aviram, R. Bardin, Y. Yogev, and E. Ashwal, "Role of cervical length measurement for preterm delivery prediction in women with threatened preterm labor and cervical dilatation," Journal of Ultrasound in Medicine, vol. 35, no. 12, pp. 2631-2640, 2016.

[34] N. B. Kunzier, W. L. Kinzler, M. R. Chavez, T. M. Adams, D. A. Brand, and A. M. Vintzileos, "The use of cervical sonography to differentiate true from false labor in term patients presenting for labor check," American Journal of Obstetrics \& Gynecology, vol. 215, no. 3, pp. 372-372.e5, 2016.

[35] M. Parra-Cordero, A. Sepulveda-Martinez, G. Rencoret, E. Valdes, D. Pedraza, and H. Munoz, "Is there a role for cervical assessment and uterine artery Doppler in the first trimester of pregnancy as a screening test for spontaneous preterm delivery?" Ultrasound in Obstetrics \& Gynecology: The Official Journal of The International Society of Ultrasound in Obstetrics and Gynecology, vol. 43, no. 3, pp. 291-296, 2014.

[36] E. Greco, R. Gupta, A. Syngelaki, L. C. Y. Poon, and K. H. Nicolaides, "First-trimester screening for spontaneous preterm delivery with maternal characteristics and cervical length," Fetal Diagnosis and Therapy, vol. 31, no. 3, pp. 154-161, 2012.

[37] A. Fruscalzo, E. Mazza, H. Feltovich, and R. Schmitz, "Cervical elastography during pregnancy: a critical review of current approaches with a focus on controversies and limitations," Journal of Medical Ultrasonics, vol. 43, no. 4, pp. 493-504, 2016.

[38] H. Kim and H. S. Hwang, "Elastographic measurement of the cervix during pregnancy: Current status and future challenges," Obstetrics \& Gynecology Science, vol. 60, no. 1, pp. 1-7, 2017.

[39] M. Parra-Saavedra, L. Gomez, A. Barrero, G. Parra, F. Vergara, and E. Navarro, "Prediction of preterm birth using the cervical consistency index," Ultrasound in Obstetrics \& Gynecology: The Official Journal of the International Society of Ultrasound in Obstetrics and Gynecology, vol. 38, no. 1, pp. 44-51, 2011.

[40] N. Banos, C. Murillo-Bravo, C. Julia, F. Migliorelli, A. PerezMoreno, J. Rios et al., "Mid-trimester sonographic Cervical Consistency Index to predict spontaneous preterm birth in a low-risk population," Ultrasound in Obstetrics \& Gynecology : The Official Journal of the International Society of Ultrasound in Obstetrics and Gynecology, 2017.

[41] A. Sepúlveda-Martínez, F. Díaz, H. Muñoz, E. Valdés, and M. Parra-Cordero, "Second-Trimester Anterior Cervical Angle in a Low-Risk Population as a Marker for Spontaneous Preterm Delivery," Fetal Diagnosis and Therapy, vol. 41, no. 3, pp. 220225, 2017.

[42] M. Dziadosz, T.-A. Bennett, C. Dolin et al., "Uterocervical angle: a novel ultrasound screening tool to predict spontaneous preterm birth," American Journal of Obstetrics \& Gynecology, vol. 215, no. 3, pp. 376-376.e7, 2016.

[43] V. Nunes, J. Cross, J. E. Speich, D. R. Morgan, J. F. Strauss, and R. M. Ramus, "Fetal membrane imaging and the prediction of preterm birth: A systematic review, current issues, and future directions," BMC Pregnancy and Childbirth, vol. 16, no. 1, article no. $387,2016$.

[44] S. Olgan and M. Celiloglu, "Contraction-based uterine artery Doppler velocimetry: novel approach for prediction of preterm birth in women with threatened preterm labor," Ultrasound in Obstetrics \& Gynecology, vol. 48, no. 6, pp. 757-764, 2016.

[45] E. Albayrak, H. Y. Dogru, Z. Ozmen et al., "Is evaluation of placenta with real-time sonoelastography during the second trimester of pregnancy an effective method for the assessment of spontaneous preterm birth risk?" Clinical Imaging, vol. 40, no. 5, pp. 926-930, 2016.

[46] A. P. Lemos, F. E. Feitosa, E. Araujo Junior, H. N. Feitosa, J. G. Pereira, R. M. Mota et al., "Delivery prediction in pregnant women with spontaneous preterm birth using fetal adrenal gland biometry," The Journal of Maternal-Fetal \& Neonatal Medicine : The Official Journal of the European Association of Perinatal Medicine, the Federation of Asia and Oceania Perinatal Societies, the International Society of Perinatal Obstet, vol. 29, no. 23, pp. 3756-3761, 2016.

[47] J. Morales-Roselló, A. Khalil, S. Salvi, R. Townsend, Y. Premakumar, and A. Perales-Marín, "Abnormal Middle Cerebral Artery Doppler Associates with Spontaneous Preterm Birth in Normally Grown Fetuses," Fetal Diagnosis and Therapy, vol. 40, no. 1, pp. 41-47, 2016.

[48] H. Honest, "Accuracy of cervicovaginal fetal fibronectin test in predicting risk of spontaneous preterm birth: systematic review," BMJ, vol. 325, no. 7359, pp. 301-301.

[49] V. Berghella and G. Saccone, "Fetal fibronectin testing for prevention of preterm birth in singleton pregnancies with threatened preterm labor: a systematic review and metaanalysis 
of randomized controlled trials," American Journal of Obstetrics \& Gynecology, vol. 215, no. 4, pp. 431-438, 2016.

[50] N. L. Hezelgrave, K. Kuhrt, K. Cottam, P. T. Seed, R. M. Tribe, and A. H. Shennan, "The effect of blood staining on cervicovaginal quantitative fetal fibronectin concentration and prediction of spontaneous preterm birth," European Journal of Obstetrics \& Gynecology and Reproductive Biology, vol. 208, pp. 103-108, 2017.

[51] M. Bruijn, J. Vis, F. Wilms et al., "Quantitative fetal fibronectin testing in combination with cervical length measurement in the prediction of spontaneous preterm delivery in symptomatic women," BJOG: An International Journal of Obstetrics \& Gynaecology, vol. 123, no. 12, pp. 1965-1971, 2016.

[52] M. S. Esplin, M. A. Elovitz, J. D. Iams et al., "Predictive accuracy of serial transvaginal cervical lengths and quantitative vaginal fetal fibronectin levels for spontaneous preterm birth among nulliparous women," Journal of the American Medical Association, vol. 317, no. 10, pp. 1047-1056, 2017.

[53] E. Y. Jung, J. W. Park, A. Ryu, S. Y. Lee, S.-H. Cho, and K. H. Park, "Prediction of impending preterm delivery based on sonographic cervical length and different cytokine levels in cervicovaginal fluid in preterm labor," Journal of Obstetrics and Gynaecology Research, vol. 42, no. 2, pp. 158-165, 2016.

[54] T. Nikolova, O. Bayev, N. Nikolova, and G. C. Di Renzo, "Comparison of a novel test for placental alpha microglobulin-1 with fetal fibronectin and cervical length measurement for the prediction of imminent spontaneous preterm delivery in patients with threatened preterm labor," Journal of Perinatal Medicine, vol. 43, no. 4, pp. 395-402, 2015.

[55] L. Mesic Ethogic, D. Micic, F. Omeragic, R. Kovac, and S. Fazlagic, "IGFBP-1 marker of cervical ripening and predictor of preterm birth," Medicinski Glasnik: Official Publication of the Medical Association of Zenica-Doboj Canton, Bosnia and Herzegovina, vol. 13, no. 2, pp. 118-124, 2016.

[56] G. U. Eleje, E. C. Ezugwu, A. C. Eke et al., "Accuracy of a combined insulin-like growth factor-binding protein-1/interleukin6 test (Premaquick) in predicting delivery in women with threatened preterm labor," Journal of Perinatal Medicine, vol. 45, no. 8, pp. 915-924, 2017.

[57] M. M. C. Bruijn, J. Y. Vis, F. F. Wilms et al., "Comparison of the Actim Partus test and the fetal fibronectin test in the prediction of spontaneous preterm birth in symptomatic women undergoing cervical length measurement," European Journal of Obstetrics \& Gynecology and Reproductive Biology, vol. 206, pp. 220-224, 2016.

[58] R. Tripathi, S. Tyagi, Y. M. Mala, N. Singh, N. B. Pandey, and P. Yadav, "Comparison of rapid bedside tests for phosphorylated insulin-like growth factor-binding protein 1 and fetal fibronectin to predict preterm birth," International Journal of Gynecology \& Obstetrics, vol. 135, no. 1, pp. 47-50, 2016.

[59] J. C. Melchor, A. Khalil, D. Wing, E. Schleussner, and D. Surbek, "Prediction of preterm delivery in symptomatic women using placental alpha-microglobulin-1, fetal fibronectin and phosphorylated insulin-like growth factor-binding protein-1 tests: systematic review and meta-analysis stratified by risk," Ultrasound in Obstetrics \& Gynecology: The Official Journal of the International Society of Ultrasound in Obstetrics and Gynecology, 2018.

[60] A. S. Ozgu-Erdinc, S. Cavkaytar, A. Aktulay, U. Buyukkagnici, S. Erkaya, and N. Danisman, "Mid-trimester maternal serum and amniotic fluid biomarkers for the prediction of preterm delivery and intrauterine growth retardation," Journal of Obstetrics and Gynaecology Research, vol. 40, no. 6, pp. 1540-1546, 2014.
[61] M. Oz, B. Polat, E. Ozgu, K. D. Seckin, C. Tasin, and N. Danisman, "Interleukin-6 and C-reactive protein levels in the amniotic fluid as indicators of preterm delivery in Turkish women," Clinical and Experimental Obstetrics \& Gynecology, vol. 42, no. 6, pp. 801-804, 2015.

[62] A. Kesrouani, E. Chalhoub, E. El Rassy et al., "Prediction of preterm delivery by second trimester inflammatory biomarkers in the amniotic fluid," Cytokine, vol. 85, pp. 67-70, 2016.

[63] S. Cetinkaya, G. Ozaksit, E. H. Biberoglu, A. Oskovi, and A. Kirbas, "The value of acute phase reactants in predicting preterm delivery," The Journal of Maternal-Fetal \& Neonatal Medicine: The Official Journal of the European Association of Perinatal Medicine, the Federation of Asia and Oceania Perinatal Societies, the International Society of Perinatal Obstet, pp. 1-8, 2017.

[64] S. M. Kim, R. Romero, J. Lee, P. Chaemsaithong, M. W. Lee, N. Chaiyasit et al., "About one-half of early spontaneous preterm deliveries can be identified by a rapid matrix metalloproteinase8 (MMP-8) bedside test at the time of mid-trimester genetic amniocentesis," The Journal of Maternal-Fetal \& Neonatal Medicine: The Official Journal of the European Association of Perinatal Medicine, the Federation of Asia and Oceania Perinatal Societies, the International Society of Perinatal Obstet, vol. 29, no. 15, pp. 2414-2422, 2016.

[65] S. E. Lee, S. C. Kim, K. H. Kim, M. S. Yoon, W. K. Eo, A. Kim et al., "Detection of angiogenic factors in midtrimester amniotic fluid and the prediction of preterm birth," Taiwanese Journal of Obstetrics \& Gynecology, vol. 55, no. 4, pp. 539-544, 2016.

[66] M. Nadeau-Vallee, D. Obari, C. Quiniou, W. D. Lubell, D. M. Olson, S. Girard et al., "A critical role of interleukin-1 in preterm labor," Cytokine \& Growth Factor Reviews, vol. 28, pp. 37-51, 2016.

[67] Y. Hatakeyama, H. Miura, A. Sato et al., "Neutrophil elastase in amniotic fluid as a predictor of preterm birth after emergent cervical cerclage," Acta Obstetricia et Gynecologica Scandinavica, vol. 95, no. 10, pp. 1136-1142, 2016.

[68] X. Jia, "Value of amniotic fluid IL-8 and Annexin A2 in prediction of preterm delivery in preterm labor and preterm premature rupture of membranes," The Journal of Reproductive Medicine, vol. 59, no. 3-4, pp. 154-160, 2014.

[69] O. Cetin, E. Karaman, B. Boza, N. Cim, and H. G. Sahin, "Maternal serum calponin 1 level as a biomarker for the shortterm prediction of preterm birth in women with threatened preterm labor," The Journal of Maternal-Fetal \& Neonatal Medicine: The Official Journal of the European Association of Perinatal Medicine, the Federation of Asia and Oceania Perinatal Societies, the International Society of Perinatal Obstet, vol. 26, pp. 1-10, 2017.

[70] R. Sharony, D. Dayan, D. Kidron et al., "Is the ratio of maternal serum to amniotic fluid AFP superior to serum levels as a predictor of pregnancy complications?" Archives of Gynecology and Obstetrics, vol. 293, no. 4, pp. 767-770, 2016.

[71] I. Hudić, B. Stray-Pedersen, J. Szekeres-Bartho et al., "Maternal serum progesterone-induced blocking factor (PIBF) in the prediction of preterm birth," Journal of Reproductive Immunology, vol. 109, pp. 36-40, 2015.

[72] H. Isik, O. Aynioglu, A. Sahbaz et al., "Can plateletcrit, an underestimated platelet parameter, be related with preterm labour?" Journal of Obstetrics \& Gynaecology, vol. 35, no. 7, pp. 676-680, 2015.

[73] K. Soghra, S. Zohreh, A. K. Kobra, and M. M. Reza, "Single measurement of salivary estriol as a predictor of preterm birth," 
Pakistan Journal of Biological Sciences, vol. 17, no. 5, pp. 730-734, 2014.

[74] V. O. Gunko, T. N. Pogorelova, and V. A. Linde, "Proteomic profiling of the blood serum for prediction of premature delivery," Bulletin of Experimental Biology and Medicine, vol. 161, no. 6, pp. 829-832, 2016.

[75] E. Baraldi, G. Giordano, M. Stocchero et al., "Untargeted Metabolomic Analysis of Amniotic Fluid in the Prediction of Preterm Delivery and Bronchopulmonary Dysplasia," PLoS ONE, vol. 11, no. 10, p. e0164211, 2016.

[76] J. G. Cecatti, R. T. Souza, K. Sulek et al., "Use of metabolomics for the identification and validation of clinical biomarkers for preterm birth: Preterm SAMBA," BMC Pregnancy and Childbirth, vol. 16, no. 1, 2016.

[77] M. A. Elovitz, L. Anton, J. Bastek, and A. G. Brown, "Can microRNA profiling in maternal blood identify women at risk for preterm birth?” American Journal of Obstetrics \& Gynecology, vol. 212, no. 6, pp. 782-782.e5, 2015.

[78] F. Varol, N. Er, N. Süt, and C. N. Sayin, "A local study on antenatal features of preterm births at 26-32 versus 33-36 weeks of pregnancy," Gynecology Obstetrics \& Reproductive Medicine, vol. 24, no. 1, pp. 1-6, 2018.

[79] E. Kurtul Çam, N. Demircan, Ü. Özmen Bayar, F. Köktürk, and İ. İnan Arıkan, "Risk factors causing preterm labor," Gynecology Obstetrics \& Reproductive Medicine, vol. 19, no. 1, pp. 7-11, 2016. 


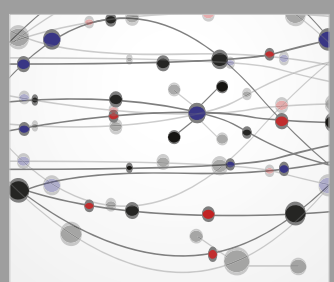

The Scientific World Journal
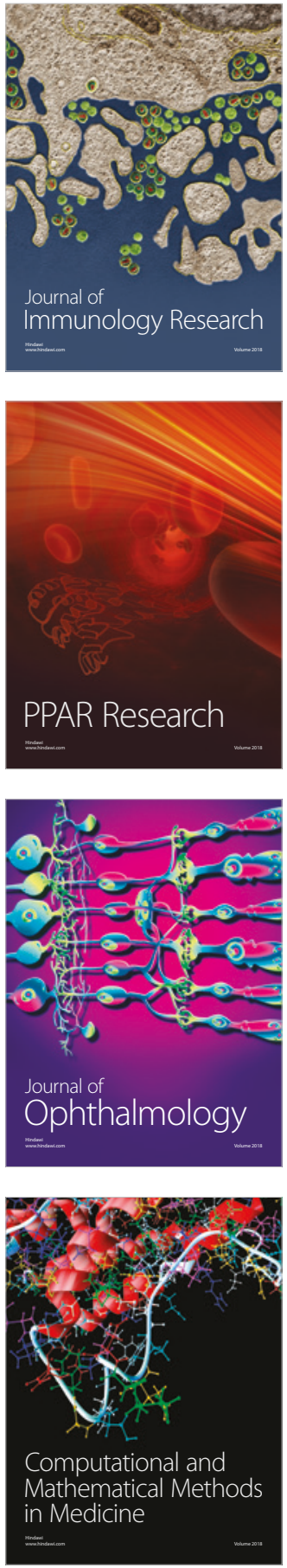

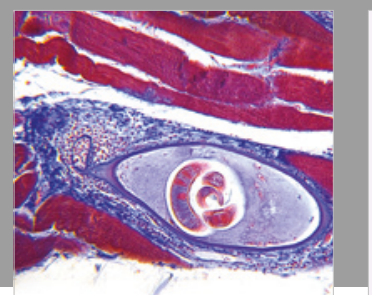

Gastroenterology Research and Practice

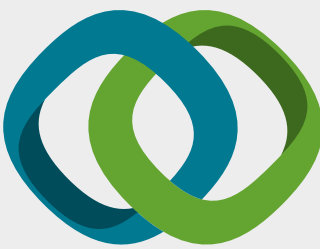

\section{Hindawi}

Submit your manuscripts at

www.hindawi.com
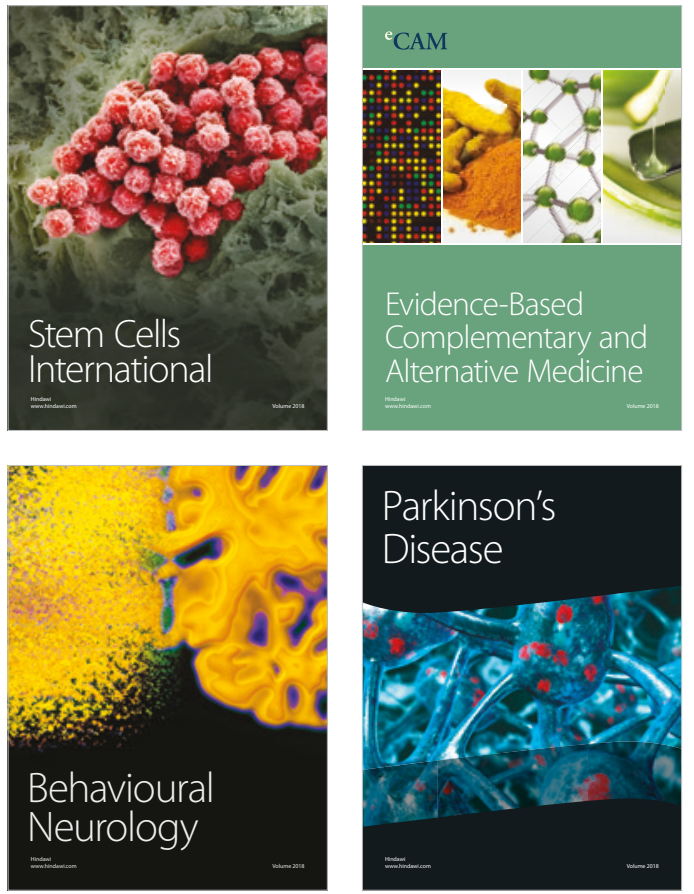

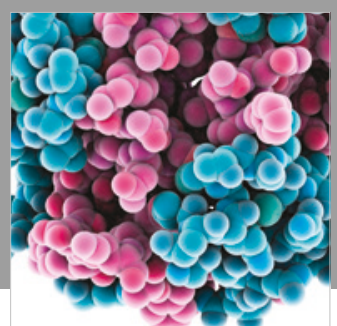

ournal of

Diabetes Research

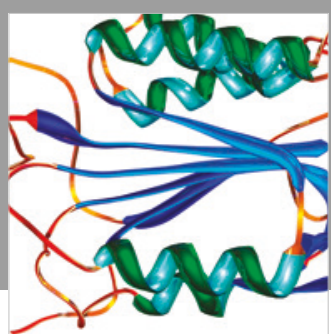

Disease Markers
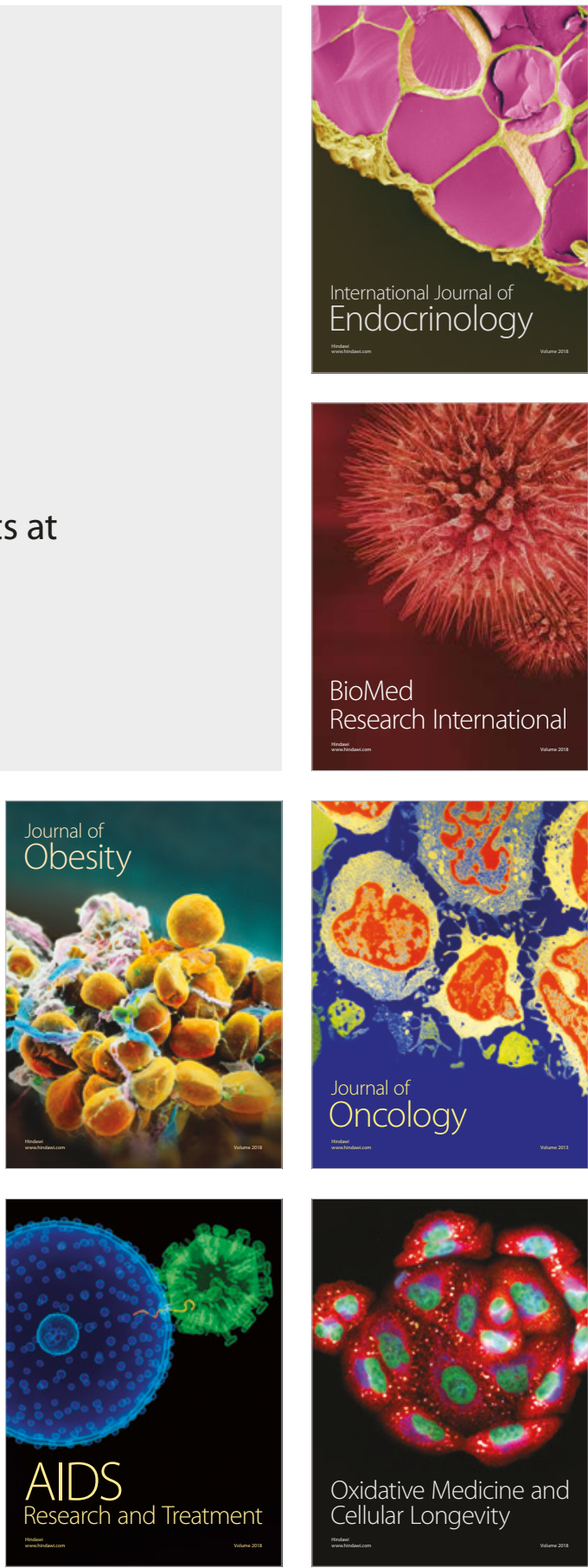